at ordinary temperatures. Although the juices were unpasteurized and no aseptic precautions were observed, the treated juice (Rival 5) showed no obvious fermentation during the period of observ. ation (four weeks); some slight mould growth, however, occurred. Juice which had been de-aerated and bottled under carbon dioxide showed even greater stability. The untreated juice (Rival 3) was rapidly fermenting within three days.

It is thus apparent that ion-exchange treatment of apple juice effects the removal or partial removal of nutrients necessary for the growth of micro-organisms. Juices so treated become very much less liable to microbiological spoilage. Further experiments on this and other aspects of the work are in progress. If it should prove practicable to produce similar changes in juice composition affecting the growth of micro-organisms by ion-exchange treatment on a commercial scale, then the industrial production of apple juice-and possibly of other fruit juicesmight be radically changed in respect of processing procedure, storage and the ultimate stability of the finished product. It is obvious also that the results here recorded open up far-reaching possibilities in connexion with the preparation and stability of other types of fruit products, for example, cider and perry.

We wish to thank the Permutit Co., Ltd., for samples of the adsorbents used in this work.

${ }^{1}$ Englis and Fiess, Ind. Eng. Chem., 34, 864 (1942).

${ }^{2}$ Matchett, Legault, Nimmo and Notter, Ind. Eng. Chem., 36, 851 (1944).

${ }^{3}$ Buck and Mottern, Ind. Eng. Chem., 37, 635 (1945); 39, 1087 (1947).

' Riches, Chem. and Ind., 43, 656 (1947).

'Davies, Chem. and Ind., 4, 51 (1948).

\section{THE ROYAL SANITARY INSTITUTE}

THE Annual Congress of the Royal Sanitary Institute was held at Harrogate this year during May 24-28. On May 28, a joint meeting was held with the Food Group of the Society of Chemical Industry to discuss the cleaning and sterilizing of plant in the food industry. After an introduction by Dr. E. B. Hughes, chairman of the Food Group, papers were presented by Dr. J. G. Davis on "The Cleaning and Sterilizing of Dairy and Ice Cream Plant", by Mr. H. J. Bunker on "The Hygiene of Beer Production and Consumption", and by Mr. D. H. F. Clayson and Mr. C. W. Chater on "The Cleaning and Sterilization of Plant and Utensils in the Food Industry".

Dr. Davis defined cleaning as the removal of all residues and particularly those which serve as a food for bacteria. Sterilization is only a finishing process, cleaning being the more important operation. Unless all food residues are removed, the few remaining bacteria can proliferate rapidly in the presence of food, moisture and warmth. A reasonable standard for commercial sterility or 'sanitization' is one colony per ml. capacity or per square centimetre of surface.

Although different methods can be used successfully, all methods conform to certain fundamental principles, which were enumerated as follows :

(1) Cleaning and sterilizing must always be regarded as distinct and different operations.

(2) The first treatment should always be a cool or tepid water rinse. Cold water hardens the fat, and hot water denatures the water-soluble proteins which with calcium salts form a strongly adhering film. Hard water should be softened.

(3) The second treatment should be with a suitable detergent solution applied as hot as possible. This emulsifies the fat and proteins, partially saponifying or hydrolysing them, and finally washes away the broken-down and loosened milk constituents. The emulsifying power of the detergent solution is related to the surface tension and to its ability to penetrate between dried-on milk film and the metal surface.

(4) Should any milkstone be visible after the detergent treatment, this must be removed by a weak acid solution, as otherwise the sterilizing will not be efficient. Milkstone does not normally form unless milk is heated, and so is found chiefly in the hot sections of pasteurizing plant. Frequency of acid treatment depends on the type and individuality of the plant, the milk supply, the time of running, the temperature used and other variable factors.

(5) 'Scale', or 'fur', resulting from the use of hard water is inimical to sterilizing, and can be particularly troublesome in bottle-washing machines. As with milkstone, the dilute acid treatment is necessary for its removal. In order to avoid corrosion, inhibitor preparations should be incorporated in the acid solution. These generally consist of organic nitrogen compounds of the quinoline type.

(6) Special precautions must be observed with certain metals, particularly aluminium and tin. Detergents for use with aluminium and tin should contain at least 25 per cent silicate, and preferably no caustic soda at all. The incorporation of about 10 per cent of sodium sulphite has been recom. mended to prevent corrosion of tinned plate, but this is only rarely used in Great Britain. All metals, including stainless steel ('crevice attack'), can suffer corrosion with chlorine, especially if used with soft water which has a low $p$ H.

(7) After cleaning, equipment should be left either dry or in contact with the sterilizing solution. The better method is to keep thoroughly clean plant in a dry condition, as bacteria cannot grow without moisture.

In discussing dairy equipment, it was emphasized that on the farm the best results can be obtained with very simple and home-made equipment. On farms where the buildings, etc., are in very bad condition it has been shown that it is possible to produce milk of good-keeping quality provided there is a good supply of clean, cold water, and the utensils are thoroughly washed.

On the other hand, in farms with excellent build. ings and the very latest and often expensive equipment, poor-keeping quality in milk is sometimes found where there is a lack of clean, cold water, and where apparently trivial but, in reality, serious mistakes are made in the cleaning and sterilizing of the equipment.

Churns are generally treated by pre-rinse, hot rinse or hot detergent, hot rinse, steam, and sometimes hot air at $240^{\circ} \mathrm{F}$. The author expressed his preference for a final steaming which left the churn very hot at the mouth rather than for a final treatment by hot air. For containers which have to be emptied and cleaned quickly, a preference was expressed for a chlorine wash rather than for steam for sterilizing.

Pipelines should be taken down every day; but some dairies get satisfactory results by only stripping 
every second or third day. On the Continent, plant is treated by dilute nitric acid, detergent and final rinse and only rarely taken down; but this method has not been generally adopted in Great Britain. Pasteurizing plant should be dismantled at least once every day and thoroughly cleaned and sterilized. The modern high-temperature-short-time pasteurizing plant is not susceptible to thermophilic growth as is the 'holder' plant.

Only a very small proportion of bottles are now scalded with steam or hot water. Most big dairies employ bottle-washing machines which use hot detergent at $140^{\circ} \mathrm{F}$., which both cleans and sterilizes bottles. It is important, however, to maintain rinse solutions in a satisfactory bacteriological condition.

In dealing with some special aspects of problems in the dairy industry, the author emphasized the significance of the individuality of utensils, and the effect of atmospheric temperature on the bacteriological condition of utensils and plant, the importance of the interval between sterilizing and use, and further pointed out that the larger the container the smaller is the relative contamination by a given number of bacteria per unit of surface.

Hypochlorite solution used for sterilizing is sometimes used at an unnecessarily high strength, about 150 p.p.m. at a minimum temperature of $120^{\circ} \mathrm{F}$. for a minimum time of $2 \frac{1}{2}$ minutes being recommended. Too strong a chlorine solution might lead to serious corrosion, especially when the water is soft.

Mr. H. J. Bunker, in dealing with the hygiene of beer production and consumption, briefly described stages in the making of beer. The malting of the barley is followed by the grinding of malt and mashing of the ground malt or grist. The wort is next boiled for some time and the hops added. The boiled wort is then pitched or inoculated with yeast, and fermentation allowed to proceed. The beer is finally run to cellars, where it is emptied into casks or held in a container from which, after a few days, it is bottled, with or without filtration, according to the type of beer. After bottling it may be pasteurized, but in Great Britain the greater part of the bottled beer is not heat-treated.

On account of its high acidity, beer is one of the safest of foods from the bacteriological point of view. The $p H$ of beer is usually about 4 and this probably explains why pathogenic bacteria are always absent. In addition, hops and alcohol are factors inhibitory to bacteria. The prolonged boiling of the wort gives complete sterility at one stage, and the author was of the opinion that the maintenance of clean mains was the most important item of hygiene in the brewery. The cleaning of these mains must be a regular operation, for which caustic soda solution is commonly used.

Beer is now generally cooled in a built-in type of cooler which has the advantage that delivery is achieved in a closed system without intermediate exposure to infection.

A point of some importance in the cleaning of brewery plant, which might consist of copper, wood, slate, aluminium, stainless steel or wax-lined materials, is the fact that in course of time a deposit known as 'beerstone' forms on the side of the fermenting vessel. The modern brewer prefers to remove this beerstone and thus eliminate what would otherwise become a dangerous lurking place for microorganisms.

Bottles and bottle-filling machines require particular attention. In bottle-washing, caustic soda is the chief constituent of the detergent, and the general standard of cleanliness in these machines is now very high.

Preservatives are not added to bottled beers, the old idea that the brewer adds chemicals to beer being entirely erroneous. The only preservative which is permitted in brewing is sulphur dioxide.

One of the chief sources of contamination in breweries is old cellar floors which, when they become cracked, are difficult to clean. Such floors can be treated with chloride of lime or 'Antiformin' (sodium hydrochlorite and sodium hydroxide). Phenolic antiseptic should not be used, for obvious reasons.

Mr. Bunker next dealt with the very important aspect of hygiene in beer houses and named three methods for dealing with the problem of glasses : (a) the automatic glass-washing machine; (b) the self-emptying sink; (c) the addition of some suitable detergent or antiseptic to the rinse water. He expressed a preference for the third method and described recent work on the use of quaternary ammonium compounds for this purpose.

Dealing finally with the question of drying cloths, Mr. Bunker said that most|bar-tenders prefer to dry and polish glasses after rinsing. If the cloths are allowed to get dirty they may well put back on the glasses more organisms than were there before drying. It is essential that any cloths used should be in a good bacteriological condition.

$\mathrm{Mr}$. Clayson and Mr. Chater, in dealing with the present-day communal feeding in restaurants and canteens, stated that the effects of inadequate hygiene in the kitchen may be serious. Although machine-washing is growing in restaurant kitchens this method is not foolproof, and in the authors' experience there is not much difference between the results of hand-washing and machine-washing.

They pointed out that dirt is not defined from the legal point of view and that it is necessary, in order to comply with the Food and Drugs Act (1938), to define processes that can be relied upon to destroy or remove pathogenic organisms if they should be present. This definition would have to be in chemical or physical terms in relation to detergent concentrations, temperatures, times, etc. With highly glazed or polished articles the appearance is a very good guide to their hygienic condition. This question is important because the removal of soiling deposits from food utensils is an important stage in securing a satisfactory hygienic condition.

Instead of stating that a certain organism is destroyed in a certain time at a certain temperature, it is preferable to refer to destruction-rates, for example, the decimal reduction time, which is the time required to reduce the count to one-tenth of what it was originally. The decimal reduction time of most intestinal organisms is of the order of one minute at $140-145^{\circ} \mathrm{F}$. At $160^{\circ} \mathrm{F}$. or over the decimal reduction time values of staphylococci and strepto. cocci are a matter of seconds only.

Thermoduric organisms are of little sanitary significance. 'Sanitization' may therefore be defined as a treatment which eliminates pathogenic and foodpoisoning micro-organisms but which may not destroy thermoduric organisms.

The extent of dispersion of soiling material depends upon the volume of wash water, the mechanical force applied, the volume of rinsing water and the frequency with which the washing and rinsing waters are changed. If the sterilization process consists of immersion in hot water or disinfectant solution, a satisfactory cleaning has the additional advantage 
that any remaining bacteria are easily dislodged from the surface. With satisfactory washing it is possible to achieve a high degree of sterility by immersing the articles for a much shorter time in the rinse water than would be required if all the bacteria remained attached to the surface.

The United States Public Health Service Code requires: (1) a cleaning process with a detergent solution at $110-120^{\circ} \mathrm{F}$.; (2) sterilization (with a choice of four methods); and (3) drying with clean cloths, or preferably by evaporation. The standards required in the United States give, apparently, a very wide margin of safety if the conditions for high. temperature-short-time pasteurization, that is, $162^{\circ} \mathbf{F}$. for not less than fifteen seconds, can be taken as a guide for the destruction of pathogenic organisms. Evaporation after hot-water rinsing is preferable to drying by a cloth.

For utensils with thick or dried-on deposits, machines which allow a long period of contact with detergent solution are necessary. An important point in the design of such machines is the avoidance of excessive carry-over of the detergent solutions to the rinsing compartments.

A plant used for the preparation, service and storage of food needs the same if not more attention from the hygienic point of view than the multiservice utensils.

To obtain a bactericidal effect with steam it is essential to keep the steam in an enclosed, space with a comparatively small vent and to continue stéaming for at least three minutes after steam issues from the vent at over $205^{\circ} \mathrm{F}$.

The authors suggested that it would be sometimes advisable to employ two different types of sterilizing treatment, for example, steam and hypochlorite solution, with the object of destroying organisms which might escape one of these treatments, but no experimental evidence was quoted in support of this view. Hypochlorite treatment must, of course, be followed by further rinsing with cold water.

\section{WIGAN MINING COLLEGE}

$F$ OUNDED on October 27, 1857, Wigan and District Mining and Technical College has just celebrated its ninetieth anniversary. In its first session the average attendance was 15; now it has some 2,800 students. The intervening ninety years show a continuous record of expansion and progress in spite of many difficulties. Like most higher institutions of learning in Britain to-day, the College is overcrowded and badly in need of extended accom. modation and additional facilities, particularly for postgraduate and research work. Founded primarily to develop mining education, and still maintaining a leading position in that field, it has never confined itself to mining alone. Its range of work covers also engineering, chemistry, physics, geology, biology, mathematics, building, commerce, economics, art, and other subjects.

A special feature of the work of the College is the provision of complete full-time courses for the degrees of the University of London in mining, engineering, general science, chemistry, physics, geology, mathematics and economics. The College is inspected and recognized by the University in connexion with the mining and engineering degree courses. It is also recognized by the Board for Mining Examinations, the Board of Trade, the Institution of Civil Engineers, the Institution of Mining Engineers, the Royal Institute of Chemistry, the Institute of Physics, etc. It is the headquarters of the Manchester Geological and Mining Society and provides accommodation for meetings of many other scientific, technical and professional bodies. A notable feature of its work is the development of its library and refectory services and of student activities. It has in Christopher Park one of the finest athletic grounds in the north of England.

A meeting to celebrate the ninetieth anniversary was held in the College hall on June 7. This was attended by a very representative gathering, including educationists, scientific workers, industrialists, and government and local officials, as well as governors, staff and students. The chairman of the Governing Body, Colonel J. S. A. Walker, presided, and the principal, Dr. J. F. S. Ross, gave a brief survey of the history and work of the College, directing attention to the devoted service it had received from its founders and their successors, its longstanding regional character and independence-it receives very substantial grants from the Lancashire and Wigan Education Authorities but possesses its own freehold land and buildings and has its own autonomous governing body-and to the development within it of a truly educational and collegiate spirit. The chairman of the General Purposes Committee, County Councillor A. Guest, who has been a governor of the College for the last third of a century, also referred to aspects of its history and directed attention to its high reputation at home and abroad. Notwithstanding the invaluable help of local authorities, the College needs greater financial resources, and he thinks it should receive these on lines comparable with those on which university colleges are helped by the University Grants Committee.

Sir Charles Ellis, scientific member of the National Coal Board, gave an address on "The Place of Science in a Technical Training". After commenting on the high reputation of the College in science and industry -he had heard from everyone in a position to judge that Wigan-trained people had a sound knowledge of and lively interest in the fundamental sciences and a genuine appreciation of the means of applying them to technological problems-Sir Charles referred to the distinction between industrial scientists and research scientists, and denied the validity of any difference of status between them. He mentioned the manifold duties of scientific men in connexion with the National Coal Board : while the majority of them are in the colliery chemical services and carry out their scientific duties in daily contact with industry, there are other groups which have more national standing. He mentioned the special group dealing with the survey of coal seams in Britain, and said that we have an accurate knowledge of the quality of our coal seams for many years ahead before they are mined. He also referred to the research group engaged on fundamental studies of coal substance. These are doing pioneer work. He went on to develop a closely reasoned argument as to the intrinsic value of scientific education, not only in relation to industry but also in inculcating a genuinely philosophical attitude to life. The address is to be published by the College in pamphlet form.

An illustrated booklet on the College has been issued in connexion with the ninetieth anniversary; copies can be obtained from the College office, price 1s. $6 d$. each. 